This is a post-peer-review, pre-copy edited version of an article published in Families, Relationships and Societies (Policy Press). The definitive publisher-authenticated version, [Funk, L.M. (2015). Constructing the meaning of filial responsibility: Choice and obligation in the accounts of adult children. Families, Relationships, and Societies, 4(3), 383-399. doi: http://dx.doi.org/10.1332/204674314X14110461145506] is available online at: http://www.ingentaconnect.com/content/tpp/frs/2015/00000004/00000003/art00003

\title{
Constructing the meaning of filial responsibility: choice and obligation in the accounts
}

\section{of adult children}

This paper reports findings from an interpretive study of filial responsibility constructions among 28 adult children with aging parents in Victoria, Canada. Participants were interviewed in-person and data were analyzed using coding and constant comparison, with attention to the content and process of talk. Participants tended to have difficulty with using the construct of responsibility to describe the support they provided for aging parents. Ambivalence was tied to symbolic associations of the construct with obligation and burden, which were difficult to reconcile with interpretations of filial relationships as loving and moral, and participants' desires to construct themselves as autonomous. Participants also sought to interpret parent support as voluntary, yet the ideal of choice was also difficult to reconcile with specific realities. The discussion highlights how the interpretive framework of "choice" may further inadvertently support political and economic goals that promote and increase the need for family care of older persons. 
Broad-level social, political, and economic contexts shape the need for and availability of family support, as well as individual-level interpretations and meanings of such support. In Canada and other Western and European nations, health and social care budgets, including home and community care, are under increasing scrutiny. Though families already provide the vast majority of support for older persons, care reforms and changes to health and social care services over several decades have led to increasing reliance on families to assume primary roles in this regard (Chappell, 1993; Fast and Keating, 2000).

During this time, attention has also been directed by researchers, practitioners and policy makers to adult children's perceptions and interpretations of filial responsibility, with a focus on identifying causal motivations that promote care provision. In contrast, the complex subjective processes and broader social frameworks informing constructions of the meaning of responsibility are less often explicitly addressed. In this paper, I present findings from an indepth, interpretive analysis of how 28 adult children construct the meaning of responsibility for aging parents..

\section{Literature Review}

In existing research, filial responsibility is commonly operationalized as an attitude or belief (related to obligation) that potentially motivates care behaviours (e.g., Franks, Pierce and Dwyer, 2003; Gans and Silverstein, 2006). Other literature focuses on filial care behaviours themselves, conceptualized as the enactment of filial attitudes (Donorfio, 1996).. However, filial care behaviours are not unequivocal reflections of underlying attitudes, which are only one of a range of influences on care provision, such as economic necessity (Keefe, Rosenthal and Beland, 2000; Peek, Coward and Peek, 2000; Zhan and Montgomery, 2003). 
From a subjective perspective, feelings of (and thoughts about) responsibility for others are core features of caregiving experiences (Twigg and Atkin 1994; Calasanti and Slevin 2001; Wuest, 1997). Ambivalence has also been documented in filial caregiving relationships (Abel, 1990; Lang, 2004; Pillemer and Lüscher, 2004), referring to feeling torn between contradictory emotions, internalized ideals, or role demands. Specific examples include the tension between what family caregivers feel and what they believe they should feel (MacRae, 1998); and between internalized ideals such as reciprocity and solidarity (George, 1986); independence and obligation (Holroyd, 2001); emotional closeness and distance (Bengtson et al., 2002); and altruism and self-interest (Hillcoat-Nallétamby and Phillips, 2011). Ambivalence can stem from historically rooted yet shifting patterns of parentchild relations, and from conflicts between social roles (e.g., employee) and structural constraints (e.g., cultural norms; gender inequality; geographic distance: Connidis and McMullin, 2002; Hillcoat-Nallétamby and Phillips, 2011).

Ambivalence may be particularly implicated in relation to filial responsibility, given the strong moral imperative associated with the latter concept, and the potential for conflicts with other desired social goals (such as independence, choice, and love) within complex filial relationships and structural constraints. Given this potential for ambivalence, there is greater need for comprehensive inductive examination of the process and complexities of interpreting filial responsibility (i.e., beyond substantive description). Some work in this regard suggests meanings of filial responsibility are multi-dimensional, flexible, individualized, conditional, and situation-dependent, and involve both moral and material aspects negotiated over time in families, as family members seek to maintain a positive personal identity (Gubrium, 1988; Finch and Mason, 1993; Donorfio, 1996; Holroyd, 2003). From this perspective, people 
construct meanings of obligation to kin "when they have to out of various [interpretive resources] available" (Finch and Mason, 1993, p.345). For instance, setting limits on filial responsibility can involve interpretive appeals to multiple competing responsibilities to and between various family members (Aronson, 1992; Gubrium, 1988; Piercy, 1998). Further, from this perspective cultural filial norms are fluid, actively renegotiated and redefined by adult children in response to changing social contexts and realities (Pyke, 2000; Lan, 2002).

A comprehensive understanding of the specific ways adult children interpret filial responsibility may be helpful in understanding how they cope with support provision and manage the effects on their sense of self. Interpretations or "meaning-making" are important components of personal coping (Affleck and Tennen, 1996; Gottlieb and Wolfe, 2002) and may be one means to manage ambivalence in family caregiving situations.

Because the term responsibility tends to imply a strong moral imperative, individuals may be sensitive to how they discuss this concept, so as to present their behaviours and feelings to align with traditional social norms of family relationships. Their accounts may in part reflect this process, and as such in this study I draw on the methodological approach of interpretive inquiry (Gubrium and Holstein, 2000). Specifically, I explore how participants respond to and engage with the cultural constructs of both responsibility and choice as frameworks for constructing a coherent account of parent support.

\section{Methods}

Interpretive qualitative inquiry directs attention to the functions of talk, including how individuals make sense of experiences through drawing on shared cultural and social frameworks. Instead of focusing on how social norms motivate behaviour, it examines how ideas are employed post-hoc as frameworks of meaning within which to construct accounts of 
behaviour. This approach stems from social phenomenological and ethnomethodological traditions, and the sociological understanding of the conversational use of discourse: "we categorise and interpret experience and events according to the structures available to us and in the process of interpreting, we lend these structures a solidity and a normality which is often difficult to question" (Mills, 2003, p. 56).

I conducted in-person, qualitative interviews with 28 adult children of aging parents, who were providing at least three hours of support monthly (including visiting and emotional support) to one or both parents over 65 years of age, living in or near Victoria, Canada. Recruitment involved advertisements distributed through various personal social networks and public locations. The advertisement asked for individuals willing to speak about their sense of responsibility for their parents, raising the potential for self-selection of those who feel responsible.

Participants were interviewed in-person at two points in time (approximately six months apart). Interviews were designed to facilitate accounts and interpretations of support and responsibility. At the first interview, I asked questions such as: "tell me about your sense of responsibility for your parent" and "what does your sense of responsibility feel like?" At the second interview, I encouraged participants to elaborate on their feelings of and thoughts about filial responsibility, including any changes in meaning over time. In addition, I asked targeted questions arising from analyses of the first interviews, primarily to ascertain participants' ideas about whether the term responsibility implied obligation or not, and how this fit with their perceptions of their filial relationships.

I recorded and transcribed all interviews verbatim, and analyzed these first through familiarization with each individual interview (re-reading, summaries of the descriptive 
content). Subsequent analysis was guided by the primary analytic question: "how do respondents talk about [filial] responsibility?" This question directly reflected the focus of this research on the construction of filial responsibility and parent support. Summaries addressing this question were created for each interview (and analytic memos considering this question for the sample as a whole). Additional analytic techniques included visual mapping and tables; open and thematic coding; and constant comparison within and between interviews. A constructivist, interpretive approach guided the identification of codes and themes (i.e., attending not only to the substantive content of what participants said but also how they constructed meanings). A detailed codebook was created and revised over time. Strategies to ensure rigor included: ensuring fit between research question and design elements; considering sample appropriateness; reviewing transcript accuracy; analyzing data throughout the data collection period; and using theoretical ideas cautiously as templates, rather than as narrowly circumscribed frameworks to which data are fitted (Patton, 1999; Morse et al., 2002). I conducted all interviews and analyzed the data, creating a detailed log book of methodological and analytic decisions; the process was closely supervised by a three-person academic research committee.

\section{Findings}

\section{Sample Description}

The average age of participants was 51 ( 16 women and 12 men). The majority $(n=22)$ were employed full time, and three were retired. Standardized data on income were not collected, though all participants owned homes and worked in professional or administrative occupations. The majority (27/28) were of English/European descent; one emigrated from a Spanish-speaking country in young adulthood. Ten participants had both parents still living; 
18 had only one. The parents' average age was 84 . Seventeen participants had siblings close by, nine were the sole child in town, and two had no siblings. Participants provided between 6 and 80 hours of support monthly in response to a wide range of parental care needs (data on specific needs were not collected in a standardized way).

In other publications, I have explored how these children spoke about their filial responsibility in complex ways, which provide insights into the symbolic, cultural meanings of the concept. For instance, participants acknowledged their own sense of filial responsibility as a duty or obligation, yet frequently qualified this with needing to respect their parents' autonomy (Funk, 2010a). They also rejected the idea of paying back their parents in the sense of a filial contract, highlighting interpretations emphasizing mutuality and reciprocated love (Funk, 2012). Lastly, participants also criticized individualistic cultural values as weakening filial responsibility in Canada, suggesting that adult children should not only provide care, but should want to provide care for their parents (Funk, 2010b).

In the present paper, I explore one of the most dominant inductively generated themes from the data: how participants constructed filial responsibility as their personal choice. The analysis suggests this process is particularly complex and may reflect ambivalence. Before proceeding, however, in the next section I provide a broader sense of the data, and illustrate participant difficulties with responsibility as an interpretive framework for parent support.

\section{Being and feeling responsible for parents}

In response to a specific question, all participants expressed that they generally had a sense of filial responsibility. When asked to elaborate in-depth about the feelings involved, however, some appeared to reverse their position by stating that they did not feel responsible; others appeared to express discomfort with the idea of talking about feeling responsible; and 
others qualified their sense of responsibility (i.e., as conditional). Examples will be elaborated in this section, as illustrations of the complex interpretive processes involved.

First, contradictions in talking about responsibility were evident. For example, a daughter emphasized that she does not feel responsible for her mother - rather, it is a privilege, and she enjoys helping. Yet she later comments: "everybody feels a sense of responsibility." Another participant alternated between talking about feeling responsible toward his mother, and then rejecting the sentiment. Related to this, he expressed disturbance in comments such as: "I feel like I've failed you"; "I feel like I am a contradiction"; "I don't feel responsible [for her]. I can't get over that. I'll have to think about that." This participant was acutely aware of dissonance between his personal feelings (not feeling responsible), familialistic ideals (which prioritize family responsibility), and professional ideals (valuing social responsibility through public services for older persons).

Another common pattern in talking about filial responsibility involved qualifying the concept (most evident in phrasing such as: "I'm responsible but ..."). As examples, three participants described their responsibility thusly:

Within limits, within boundaries: I mean, there's only so much I can do, right? And I don't think they have high expectations either, they don't expect me to see them every day, yet they appreciate it when I can. (daughter)

I feel responsible for my parents that, I should be doing things for them, to help them. And it's not like trying to help them that I feel that I should pay back. But it's just - I just have respect for them. (son)

I don't do it because I want the gratitude or anything. (daughter) 
In examining these and other kinds of qualifications, participants appeared to be actively setting limits and defining their behaviours as moral, which may reflect reaction and/or resistance to symbolic meanings of filial responsibility as a cultural construct. As will be elaborated below, the broader meaning of the term tends to be viewed as implying something negative or burdensome - in reaction, participants emphasized that their personal experience is not negative. For example, one participant, who would describe himself as having a sense of responsibility for his mother, was asked what it feels like: "I don't consider it a burden at all" (This response suggests the participant is reacting to a meaning he associates with the term responsibility).

As another example, one daughter, after the interview ended, expressed that the questions implied that responsibility was negative. Reviewing the transcription and recording, I paid particular attention to question wording, yet could not identify what she had described. During her second interview, I asked whether my repeated use of the word responsibility during the interview had generated this impression. She responded:

That is probably what I felt a bit. Like I thought, “This is really weird because I don't just see this as this onerous responsibility. I am choosing to do this. I want to do this.” And it's a good - like it feels natural to me. . maybe society has put a bit of a negative thing especially around parents. Our culture makes that seem like it is a negative thing.

Another daughter very clearly communicated her love for her dying mother in her interview, yet nevertheless followed up with this email (included with permission): 
Author's post-peer review, pre-copy edited version

I have thought a lot about our interview yesterday and realize that I seldom used the word 'love' ... I am sure you realize through our conversation that there is a great deal of love in my family. My mother has always espoused unconditional love and $-\ldots$ has exemplified unconditional love with her children and grandchildren. I have perhaps an overdeveloped sense of responsibility in most if not all parts of who I am .....and.....I love my mother very much, thus my commitment to supporting her to the best of my ability.

This email may represent this participant's attempt to avoid the perception that by talking about feeling responsible, she was not conveying her love for her mother. Further, one son explains why responsibility does not accurately describe his relationship with his mother:

You have a responsibility - blah. When I think of that - it's a challenge; it's a test. You must do something. You're responsible for... making sure the kitten is okay. You have to feed the kitten everyday: "if you're not responsible for the kitten you can't have one!" So it is tasks, it is burden, it is obligation. And when I think of my mom, I don't think of her in that way.

These and similar comments suggested that for some, filial responsibility implied feeling obligated or duty-bound, and thus talking about it conveys the impression that the experience is negative, one does not love one's parent, or is overly egotistical or impressed with oneself. These reactions provide further insight into the symbolic meaning of filial responsibility, which did not fit with participants' understandings of family relationships and/or how they wanted to portray them. Overall, participants appeared ambivalent about responsibility as an interpretive framework for parent support - both accepting and rejecting the construct at the level of personal meaning. As will be addressed below, ambivalence is also evident in participants' attempts to invoke a more individualistic framework for parent support - that of choice. 


\section{Parent support and care as individual choices}

Throughout their interviews, the vast majority of participants either denied the existence of social pressures for filial responsibility or suggested these did not affect their behaviour. For example, as one daughter suggested: "there are times when I feel pressure, but I think I choose to succumb to that pressure.” This same daughter expressed a strong sense of responsibility but repeatedly emphasized choice during her interview, as in:

I do [have a sense of responsibility for her], in that I would want to be there and I don't want her to suffer in terms of loneliness, or care needs, or whatever. So yes, I have some responsibility to do that. But I also don't feel, like. . . I think I'm taking that on, as opposed to it being imposed on me.

Indeed, the majority of participants frequently emphasized during their interviews that parent support was their choice. For example, another daughter was asked to describe her filial responsibility with a metaphor:

It is a burden, I see it as a bag on a stick kind of carrying it over my shoulder, which is kind of sad to look at it like that, but it is. It would be nice not to have that. But it is there because I choose to have it.

Another daughter equated talk about responsibility with feeling negative about providing support, and then emphasized choice:

I don't feel cornered. I never thought, 'oh, nobody...' It wasn't a negative like, 'now I'm painted in a corner and nobody else is gonna do it so now I've got to.' Not at all. It was an absolute choice. This would be best. 
To better understand the complex ways that participants used ideas about choice in relation to filial support, I identified and further explored several subcategories related to choice. As the data below illustrate, though choice was a dominant interpretive framework for parent support, talking in-depth about choice often involved contradictory or conflicted sentiments that suggested ambivalence. Relevant data were identified both within general conversation and in response to specific questions. The possibility of change over time was explored, though rarely was there a significant shift in how participants spoke about their roles and feelings.

I could choose otherwise. At times, participants constructed a sense of choice through emphasizing alternative possibilities and hypothetical options. For instance, some comments drew on the idea of free will, as in (from a daughter): "I could have said no mom, you can't live with us." Participants referred to how they could choose not to help or to stop supporting their parents, and cited others who did make such choices. For instance, one daughter invoked a hierarchy of responsibility in this regard: "the only choice would be if my daughter were seriously ill, that's where I would go ... so if I had to choose, I would.” Some participants also expressed that emotionally distant or difficult relationships make it more possible to choose other options. For example, one son suggested: “I don't have the kind of loving relationship with my mother that I feel I need to be there every day." Another son noted that "choice implies not doing something to care for [my father] ... if I really have a falling out with him I would not do it."

However, participants also spoke of how certain obligations necessarily follow from an initial choice to help. For instance, one daughter noted: “you don't actually have a chance to get a break from it, once you make the choice." In these ways, choice was constructed more 
as an idealized possibility (as in hypothetical choices or options), than as a reality of participants' personal experiences.

I have control in this situation. Participants also constructed a sense of choice by focusing on their control over enacting and managing support, drawing boundaries, and interpreting the meaning of support provision. For example, one son explained how he occasionally tells his mother that he cannot help with her groceries because of other plans. Other participants likewise spoke about setting limits on support provision or selecting the specific times when they interact or activities they provide. For example, a daughter expressed: "I don't call [my mother] absolutely every day"; another noted how she tries to limit her involvement: "like I don't want to go visit today so I am not driving in there today." One son also spoke about purposefully keeping the timing of his contacts random and unpredictable: otherwise, "if you set those times then are you doing it because it is a preordained obligation."

Other participants referred to choice and/or control over the subjective interpretation and emotional impacts of caregiving, as in this excerpt from one son: "the only choice you get to make ... is what this is going to mean to you." Some referred to a need to have a mindset that views support as a choice, e.g., this "is the healthiest way to do it" and comes from a “more positive place.” For example, a daughter expressed: "even though I know I have to do this. But I am choosing how to do it. Then I am in control. I feel okay with my life." Another daughter spoke of how maintaining a sense of control and coping well involves trying "not to come from a gringey place about trying to be helpful" because "I don't want to feel obligated in a way that would cause resentment more or tension.” Again, choice appears as an ideal actively constructed by participants to help them manage and keep feelings of obligation at 
bay. However, though a sense of control is important for well-being, it not the same as choice, although participants constructed it as such.

My parent doesn't need much help. Participants also perceived a sense of choice in situations involving low need for support, related to parent characteristics such as good health, function or early stages of disease. For example, as one son noted, “I don't really feel [that] I have to, in terms of my mother because my mother is so able to do so much for herself." However, even participants whose parents had greater support needs could still maintain an (albeit tenuous) sense of personal choice, for instance, by highlighting periods of relatively low need: one daughter described how "when things are holding their own, we do have some choices to make about how much we are going to do." The ideal of choice often conflicted against a reality of constraint during times of relatively high support needs (e.g., acute crises). During these times participants stated, e.g., "I need to be there and wanted to be there" (daughter); or "there was nothing about it that was an option in my mind" (daughter). In these and similar comments support was constructed as more obligatory than voluntary by referring to its instinctual quality as in: "I don't know if choice is the right word, I mean I would just do it!" (daughter). Another daughter, describing her automatic response to her mother's needs, commented, "sometimes you're in it before you realize you made the choice."

Access to informal and formal sources of help also shaped need perceptions, as in this excerpt from one daughter: "with my father, because we had services in place to help him, I probably had a choice.” Personal resources also facilitated choice. For example, one son speculated that if his mother could not afford to live in a private retirement residence, "I would have to be doing a lot more ... thank god she has money and she can live where she lives and get extra help. It would definitely change the feelings of responsibility ... then maybe 
you would get into, obligations." Likewise, a lack of feasible sources of assistance (e.g., siblings or formal services) was described in accounting for feelings of obligation. For example, one daughter recounted the time she realized her parents' level of frailty and their need to move in with her: "there was no option of [my parents] going anywhere else ... I didn't want them to go into a home, or any kind of seniors' thing." For this participant and others, the stigma of public residential care narrowed the available options.

I am internally motivated. Participants also frequently explicitly and implicitly referred to choice in relation to the internal nature of their motivations for providing support. For example, some suggested that self-interest motivated their behaviour (i.e., in contrast to or as well as altruism). For example, one son stated that "if my mom asked me to fix the stairs and she fell down the stairs because I didn't fix the stairs because it was broke, how do you feel after that right?" Another son commented:

I have a great fear of [my mom] falling! ... if she falls and becomes more infirm that makes it harder for me ... much better that I change your light bulb so you don't topple off your stool and end up in a worse situation. It is good for her but it is also good for me. Is that enlightened self-interest or what?

Grounding a sense of choice in self-interested motivations appeared more predominant among sons than daughters; sons generally espoused more individualistic worldviews overall (i.e., describing life decisions as based on personal interest). However, most of the sons in this sample had more distant or ambivalent relationships with their parents, which may partly explain an emphasis on self-interested motivations. For instance, one son who had a difficult relationship with his alcoholic mother expressed that because they are not emotionally close 
he takes a more "selfish" approach in which his actions are based "not necessarily what's best for her but what's easier for me."

However, the line between self-centred and other-focused behaviour was blurred within family relationships. Whereas references to avoiding negative personal consequences were used by some to justify a sense of choice (as above), others suggested this was a source of obligation. For instance, a daughter expressed: “you're sort of obliged because if you didn't do it [provide support] they'd be really disappointed or angry or upset," which is "a real big, negative consequence that you really wouldn't want to have." Another daughter spoke about obligation as involved when: "I don't want a crisis to happen" and "I don't want to feel negligent." In other words, apparently self-interested motivations may generate obligation when there is a desire to avoid negative consequences.

In other comments, participants constructed themselves as having choice because of the personal, internal nature of their motivations (i.e., in contrast to external pressures from others). For example, one daughter explained that responsibility was her choice because: "I can be a bad daughter if I want to, but that's my own evaluation of that." Again, however, the concept of choice was problematic, as when participants suggested there were no alternatives simply because of the strength of their internal familialistic values (often learned within families of origin). Accountability to these internalized values can thus generate obligation and is closely tied to identity. For example, one son described why he felt obligated: "they're family. It's just how it is, right?"; likewise, a daughter explained: “it is so deeply ingrained in my psyche, in my upbringing, in my history." Another son expressed a sense of inevitability about his mother's increasing needs for support; responding to her needs is a personal moral imperative: "it's the right thing, in the same way that it is the right thing to pay your property 
taxes." Other participants referred to being indebted according to the principle of delayed reciprocity, as in: "obligation because of all she did for me" (son).

I want to do this. An emphasis on internal motivations continued within another closely related subtheme invoked by participants: that of wanting to help, as in: "I'm doing this because I want to" (son). For example, one daughter spoke of a time she made a "conscious decision ... that what I would do for my mom would be based on what I wanted to do." Participants may have been reacting to a broader understanding of responsibility as doing things one does not want to do - i.e., "[responsibility] would mean obligations you have that you don’t particularly want" (son).

In particular, however, participants frequently referred to relational qualities such as love and affection in explaining why they wanted to help, contrasting these against ideas of duty, responsibility, and obligation. For example, one son stated that he feels responsible for his mother "but the overarching thing, the most important consideration is the fact that I like her! I care for her and she is very important to me.” For many participants, talking about responsibility might convey they do not love their parent; in reaction, they prioritized choice, and their desire to help out of love. Indeed, the ideal of a loving choice appeared in part as a familialistic social norm manifested in the interviews, as participants tended to express that children should want to help their parents (Funk, 2010b).

Applying the concept of choice to a loving relationship is not straightforward, however, as evident in other comments from participants. Love can involve a compulsion to help that precludes the idea of choice. For example, one son maintained that supporting his parents is unconditional because he is motivated by love: "it is not a choice." A daughter also expressed contradictory ideas about love and choice: 
If there is the love there, an unconditional love, then it is a very simple choice and there is no degree of obligation. Because you care so much that you wouldn't do anything else. So you are going to make the caring choice every time if you love someone. And you won't feel any negativity, about giving ... [with obligation] there is that degree of negativity because obligation sounds like "I really don't want to but I have to." If you love someone, you want to. . There is no other choice. Yeah, so you want to.

As a final example, another daughter, after describing her responsibility for her mother, stated:

P: I don't know, it's just part of caring for my mother, comes with love and everything it's just - it's there. It's not something I can separate.

I: So in that sense is it a choice?

P: ... I guess - not for me - I suppose you could choose to love less? Maybe. I guess it depends on your original relationship or if you have a falling out or anything.

Further, whether or not one wants to help in specific instances varies depending on the nature of the tasks and structurally generated constraints. For example, one daughter, employed full time and "juggling a lot of things," expressed that whether her responsibility feels obligatory and burdensome is influenced by how much is on her list for the day. Less urgent and more discretionary tasks (e.g., decorating her mother's balcony) are those she is more inclined to want to do. Another daughter spoke of how visiting felt more obligatory when it competed with other responsibilities. Another daughter's mother refused painkillers after an operation, and phoned one morning asking to be driven to the hospital for pain. Thus, both her own work and driving her son to college were "out the window"; she described this as feeling like obligation, and emotionally draining. 
In sum, participants commonly attempted to invoke the interpretive framework of choice in parent support (often in response or contrast to responsibility and obligation). However, their use of the concept of choice to understand their experiences involved some contradiction, uncertainty or ambivalence: for instance, participants suggested they had a choice because they could choose otherwise (even if they did not), or because they had some degree of control over how they enacted and interpreted their filial role. They also suggested they had a choice because they were internally motivated to help their parent, yet truly selfinterested actions are limited in relationship with others, in which love can compel one to help as an automatic response, particularly during times of need or in the absence of other sources of help. Lastly, though participants rejected the idea that they were externally compelled by others to help their parent(s), they often described their own internalized normative standards as having an obligatory quality.

\section{Discussion}

Data from this study provide insights into how adult children interpret the meaning of filial responsibility. In particular, the findings highlight ambivalence in regard to both responsibility and choice when describing support for aging parents. Symbolic associations of responsibility with obligation and burden were difficult to reconcile with interpretations of filial relationships as loving and moral, and participants' desires to construct themselves as autonomous. Though adult children responded to interview questions about responsibility by emphasizing their personal choice, an in-depth analysis of their talk revealed interpretive difficulties and tensions between the ideal of choice and the relational and contextual experiences of parent support. Future research should explore the extent to which adult 
children are aware of contradiction and ambivalence in their interpretations of filial support, and whether and how this might shape caregiver well-being. This sample was relatively welleducated and with few exceptions, financially secure; their care duties were for the most part not extensive. Conducting similar studies with samples of low-income participants and those with significantly greater care responsibilities (such as co-resident caregivers) would further enhance our understanding of interpretive variations in choice and obligation. These caregivers might place greater or differing emphasis on structurally rooted constraints on parent support.

Although social and political-economic discourses that prioritize family responsibility as a moral imperative have been well documented, particularly for women (Binney and Estes, 1988; Hooyman and Gonyea, 1995; Armstrong and Kits, 2004), it has also been suggested that in post-industrial North America, structural and cultural processes reflect a pattern of individualization (Beck and Beck-Gernsheim, 2001). As such, individuals may increasingly interpret family relationships as being most appropriately rooted in choice and affection, rather than obligation (Beck and Beck-Gernsheim, 2001; Fine, 2005; Guberman, Lavoie, and Olazabal, 2011). Although participants in the present study supported a moral imperative of filial responsibility to some extent, responsibility (as obligation) did not always fit with their portrayals of family relationships, and choice was a dominant theme throughout their accounts. In part, these findings reflect the individualization of society (Jansz, 1991; Rose 1996; Beck and Beck-Gernsheim 2001) and the tendency towards ambivalence in the postmodern condition (Bauman, 1991).

Other research has illustrated how adult children try to limit their potentially boundless sense of filial responsibility (Aronson 1992; Yamamoto and Wallhagen 1998; McGrew, 1998) 
and justify limits to themselves and others by drawing on socially appropriate justifications. By rejecting the idea (though not necessarily the reality) of obligation and emphasizing choice, adult children in the present study maintain an autonomous self-image, a sense of control and positive attitude, minimizing feelings of obligation (Hochschild, 2003). Further, one recent Canadian study (Guberman, Lavoie, and Olababal, 2012; Guberman et al., 2012) reported that although baby-boomer caregivers supported filial responsibility norms, they tended not to view caregiving as an extension of normal family role or life course, and perceived a strong role for public supports to juggle multiple demands. Such interpretations may not only reflect changing cultural values and individualization; they may reflect agency in adapting to structural realities. Likewise, participants in the present study may demonstrate agency in managing ambivalence through constructing filial responsibility as a personal choice. However, social location can constrain the ability to negotiate ambivalence (Connidis and McMullin, 2002). For example, access to higher income facilitates hiring private sources of care, and it is possible that women's strongly familialistic gendered identities may limit their interpretive use of ideas such as self-interest in relation to family caregiving. More broadly, structural changes (e.g., constraints on employed caregivers that generate increased obligation; the erosion of formal services which increases parental needs for family support) might further limit the interpretive management of ambivalence among adult children.

Overall, however, both responsibility and choice are imperfect frameworks for adult children making sense of support for aging parents. Though the concept of responsibility helps participants maintain a sense of themselves as good adult children, its symbolic meanings frequently mismatch against relational realities and a cultural emphasis on autonomy. The concept of choice helps participants maintain a sense of control and imparts a voluntary or 
altruistic quality to parent support, yet the choices we make are never fully independent, as participants often acknowledged implicitly or explicitly (Funk and Kobayashi, 2009; Arksey and Glendinning, 2007; Smart and Shipman, 2004). As such, it may actually exacerbate ambivalence.

The way we talk about filial relationships at the individual level is both influenced by and further perpetuates broader discourses. As such, invoking choice as an interpretive framework may inadvertently perpetuate responsibilization: a concept that draws attention to how neoliberal governance processes encourage individuals to self-regulate to make voluntary choices to take responsibility for family (Burchell, 1996; Rose, 1996). For instance, caregivers interviewed by Luxton (2010) tended to express resignation regarding insufficient formal supports, yet emphasized their personal responsibility for care: "because they had made the choices that had culminated in their current situation, it was their private problem, not a social issue. It was something to be coped with, not something to mobilize against politically" (ibid: 172).

The substantive findings of the present study also resemble those of Stuifbergen and colleagues (2010), in which adult children rejected filial obligation as a social norm, yet expressed a strong personal obligation to parents, characterized as choice. Those authors concluded that the internalization of filial norms within personalities, experienced as free choice, reflects successful socialization. In contrast to a functionalist view, I interpret these findings as reflecting a process through which adult children responsibilize themselves to voluntarily support parents, in a political, economic and cultural context which promotes this process. 
As in other Western industrialized countries, health and social care in Canada has increasingly been guided by market principles of efficiency, competition, and cost reduction. The rise of market forces fuel attempts to minimize institutional costs of eldercare that have led to increasing reliance and demand on funded home care (Aronson and Neysmith, 1996), yet with overall reduction and/or a lack of expansion of such services (Chappell, 1993; McGrail, et al., 2008; Brackley and Penning, 2009). These and other neoliberal health system reforms generate increased expectations for families to take primary responsibility for care of older persons (Chappell, 1993; Fast and Keating, 2000). Hooyman and Gonyea (1995) describe how policy-makers use familialistic ideology (e.g. family as the best, natural source of care), "to cloak their goals of cost containment" (113); the effect is to distort the relations of care, sustaining structural inequities and limiting alternative possibilities.

Adult children in the present study both accepted and rejected familialistic norms of filial responsibility, reflecting ambivalence; in particular, they rejected responsibility in the sense of obligation. Participants appeared to prefer more individualistic frameworks to interpret their role, viewing support as ideally rooted in voluntary choice. However, this interpretation may generate additional ambivalence.

Though more relational frameworks emphasizing, for example, reciprocity and solidarity (Barnes, 2012) were also evident in participant accounts (see Funk, 2010b; Funk, 2012), they were not dominant; this may reflect their relative absence in health and social policy and practice discourse on family caregiving more broadly. Indeed, the concept of caregiving itself tends to exclude the idea of reciprocal interdependencies (Henderson and Forbat, 2002; Martin-Matthews, 2000). There is potential for relational frameworks at the level of individual meaning-making, however, to minimize ambivalence, moving beyond both 
the familialistic-obligation and individualistic-choice constructs to focus on interactional elements of support that are negotiated and exchanged in filial relationships. This requires ongoing consideration of the broader political context shaping these relationships (Barnes, 2012) and to how this context shapes and limits the available discourses for adult children seeking to make sense of their relationships with aging parents. 


\section{References}

Abel, E.K. (1990) 'Family care of the frail elderly', in E.K. Abel and M.K. Nelson (eds) Circles of care: Work and identity in women's lives. Albany, NY: State University of New York Press.

Affleck, G. and Tennen, H. (1996) 'Construing benefits from adversity: adaptational significance and dispositional underpinnings', Journal of Personality, 64: 899-923.

Arksey, H. and Glendinning, C. (2007) 'Choice in the context of informal care-giving', Health and Social Care in the Community, 15: 165-175.

Armstrong, P. and Kits, O. (2004) 'One hundred years of caregiving', in K. Grant, C. Amaratunga, P. Armstrong, M. Boscoe, A. Pederson and K. Willson (eds) Caring for/caring about: Women, home care, and unpaid caregiving. Aurora, Ontario: Garamond Press.

Aronson, J. (1992) 'Women's sense of responsibility for the care of old people: 'but who else is going to do it?', Gender and Society, 6(1): 8-29.

Aronson, J. and Neysmith, S. (1996) 'The work of visiting homemakers in the context of cost cutting in long-term care', Canadian Journal of Public Health, 87(6): 422-425.

Barnes, M. (2012) Care in Everyday Life: An ethic of care in practice. Bristol, UK: Policy Press.

Bauman, Z. (1991) Modernity and Ambivalence. Cambridge, UK: Polity.

Beck, U. and Beck-Gernsheim, E. (2001) Individualization: Institutionalized individualism and its social and political consequences. London, UK: Sage. 
Author's post-peer review, pre-copy edited version

Bengtson, V., Giarrusso, R., Mabry, J.B., and Silverstein, M. (2002) 'Solidarity, conflict, and ambivalence: Complimentary or competing perspectives on intergenerational relationships?', Journal of Marriage and Family, 64: 568-576.

Binney, E.A. and Estes, C.L. (1988) 'The retreat of the state and its transfer of responsibility: the intergenerational war', International Journal of Health Services, 18(1): 83-96.

Brackley, M.E. and Penning, M.J. (2009) 'Home-care utilization within the year of death: trends, predictors and changes in access equity during a period of health policy reform in British Columbia, Canada', Health and Social Care in the Community, 17(3): 283294.

Burchell, G. (1996) 'Liberal government and techniques of the self', In A. Barry, T. Osborne and N. Rose (eds) Foucault and political reason: Liberalism, neo-liberalism and rationalities of government, Chicago, IL: University of Chicago Press.

Calasanti, T.M. and Slevin, K.F. (2001) Gender, social inequalities and aging, Walnut Creek, CA: Altamira Press.

Chappell, N. (1993) 'Implications of shifting health care policy for caregiving in Canada', in S. Bass and R. Morris (eds), International perspectives on state and family support for the elderly, New York, NY: Haworth Press.

Connidis, I.A., and McMullin, J.A. (2002) 'Sociological ambivalence and family ties: a critical perspective', Journal of Marriage and Family, 64: 558-567.

Donorfio, L. M. (1996) Filial responsibility: Widowed mothers and their caregiving daughters, a qualitative grounded theory approach. Dissertation Abstracts International Section A. U.S., University Microfilms International. 57: 2158. 
Author's post-peer review, pre-copy edited version

Fast, J. and Keating, N. (2000) Family caregiving and consequences for carers: Toward a policy research agenda. Ottawa, Ontario, Canadian Policy Research Networks: 25.

Finch, J. and Mason, J. (1993) Negotiating family responsibilities, London: Routledge.

Fine, M. (2005) 'Individualization, risk and the body: sociology and care', Journal of Sociology, 41(3):247-266.

Franks, M., Pierce, L. and Dwyer, J. (2003) 'Expected parent-care involvement of adult children', Journal of Applied Gerontology, 22(1): 104-117.

Funk, L.M. (2012) "“Returning the love," not "balancing the books": talk about delayed reciprocity in supporting ageing parents', Ageing and Society, 32(4): 634-654.

Funk, L. M. (2010a) 'Prioritizing parental autonomy: adult children's accounts of feeling responsible and supporting aging parents', Journal of Aging Studies, 24: 57-64.

Funk, L. M. (2010b) 'The interpretive dynamics of filial and collective responsibility for aging parents', Canadian Review of Sociology, 47(1): 71-92.

Funk, L. M. and Kobayashi, K. (2009) "'Choice” in filial care work: moving beyond a dichotomy', Canadian Review of Sociology, 46(3): 235-252.

Gans, G. and Silverstein, M. (2006) 'Norms of filial responsibility for aging parents across time and generations', Journal of Marriage and Family, 68(4):961-876.

George, L.K. (1986) 'Caregiver burden: conflict between norms of reciprocity and solidarity’, in R. S. Wolf (ed) Elder abuse: Conflict in the family, Dover MA: Auburn House.

Gottlieb, B. H. and Wolfe, J. (2002) 'Coping with family caregiving to persons with dementia: a critical review', Aging and Mental Health, 6: 325-342.

Gubrium, J. F. (1988) 'Family responsibility and caregiving in the qualitative analysis of the Alzheimer's Disease experience', Journal of Marriage and the Family, 50(1): 197-207. 
Author's post-peer review, pre-copy edited version

Guberman, N., Lavoie, J.-P. and Olazabal, J. I. (2011) 'Baby-boomers and the “denaturalisation" of care-giving in Quebec', Ageing and Society, 31(7): 1141-1158.

Guberman, N., Lavoie, J.-P., Blein, L. and Olazabal, I. (2012) 'Baby boom caregivers: Care in the age of individualization,' Gerontologist, 52(2): 210-218.

Gubrium, J.F. and Holstein, J.A. (2000). 'Analyzing interpretive practice', In N. Denzin and Y. Lincoln (eds) Handbook of qualitative research, Thousand Oaks, CA: Sage.

Henderson, J. and Forbat, L. (2002) 'Relationship-based social policy: Personal and policy constructions of “care,”" Critical Social Policy, 22: 669-687.

Hillcoat-Nallétamby, S., and Phillips, J.E. (2011) ‘Sociological ambivalence revisited', Sociology, 45: 202-217.

Hochschild, A.R. (2003) The managed heart: Commercialization of human feeling, Berkeley, CA: University of California Press.

Holroyd, E. (2003) 'Chinese family obligations toward chronically ill elderly members: comparing caregivers in Beijing and Hong Kong', Qualitative Health Research, 13(3): $302-318$.

Holroyd, E. (2001) 'Hong Kong Chinese daughters' intergenerational caregiving obligations: A cultural model approach', Social Science and Medicine, 53: 1125-1134.

Hooyman, N.R. and Gonyea, J. (1995) Feminist perspectives on family care: Policies for gender justice, Thousand Oaks, CA: Sage.

Jansz, J. (1991) Person, self and moral demands: Individualism contested by collectivism, Leiden, Netherlands. DSWO Press. 
Keefe, J., Rosenthal, C. and Beland, F. (2000) 'The impact of ethnicity on helping older relatives: findings from a sample of employed Canadians', Canadian Journal on Aging, 19(3): 317-342.

Lan, P.C. (2002) 'Subcontracting filial piety: elder care in ethnic Chinese immigrant families in California', Journal of Family Issues, 23: 812-835.

Lang, F. R. (2004) 'The filial task in midlife: ambivalence and the quality of adult children's relationships with their older parents', In K. Pillemer and K. Lüscher (eds) Intergenerational ambivalences: New perspectives on parent-child relations in later life, Oxford, UK: Elsevier Ltd.

Luxton, M. (2010) 'Doing neoliberalism: perverse individualism in personal life', in S. Braedley and M. Luxton (eds) Neoliberalism and everyday life, Montreal, Canada: McGill-Queens University Press.

McGrail, K.M., Broemeling, A.M., McGregor, M., Salomons, K., Ronald, L.A. and McKendry, R. (2008) Home health services in British Columbia: A portrait of users and trends over time. UBC Centre for Health Services and Policy Research, Vancouver, B.C. http://www.chspr.ubc.ca/files/publications/2008/chspr08-15.pdf

McGrew, K.B. (1998) 'Daughters' caregiving decisions: from an impulse to a balancing point of care', Journal of Women and Aging, 10(2): 49-65.

MacRae, H. (1998). 'Managing feeling: caregiving as emotion work', Research on Aging, 20(1), 137-160.

Martin-Matthews, A. (2000) 'Intergenerational caregiving: How apocalyptic and dominant demographies frame the questions and shape the answers', in E. Gee and G. Gutman 
Author's post-peer review, pre-copy edited version

(eds) The overselling of population aging: Apocalyptic demography, intergenerational challenges, and social policy, Toronto, Ontario: Oxford University Press.

Mills, S. (2003) Michel Foucault, New York, NY: Routledge.

Morse, J.M., Barrett, M., Mayan, M., Olson, K. and Spiers, J. (2002) 'Verification strategies for establishing reliability and validity in qualitative research', International Journal of Qualitative Methods, 1(2): 1-19.

Patton, M.Q. (1999) 'Enhancing the quality and credibility of qualitative analysis', Health Services Research, 34(5Pt2): 1189-1208.

Peek, M.K., Coward, R.T. and Peek, C.W. (2000) 'Race, aging and care: can differences in family and household structure account for race variations in informal care?' Research on Aging, 22(2):117-142.

Piercy, K.W. (1998) 'Theorizing about family caregiving: the role of responsibility', Journal of Marriage and Family, 60:109-118.

Pillemer, K., and Lüscher, K. (Eds.). (2004) Intergenerational ambivalences: New perspectives on parent-child relations in later life, Oxford, UK: Elsevier Ltd.

Pyke, K. (2000) 'Normal American family' as an interpretive structure of family life among grown children of Korean and Vietnamese immigrants', Journal of Marriage and the Family, 62(1): 240-255.

Rose, N. (1996) ‘Governing 'advanced' liberal democracies', In A. Barry, T. Osborne and N. Rose (eds) Foucault and political peason: Liberalism, neo-liberalism and rationalities of government, Chicago, IL: University of Chicago Press.

Smart, C. and Shipman, B. (2004) 'Visions in monochrome: families, marriage and the individualization thesis', British Journal of Sociology, 55: 491-509. 
Author's post-peer review, pre-copy edited version

Stuifbergen, M.C., Dykstra, P.A., Lanting, K.N. and van Delden, J. (2010) 'Autonomy in an ascribed relationship: the case of adult children and elderly parents', Journal of Aging Studies, 24(4): 257-265.

Twigg, J. and Atkin, K. (1994) Carers perceived: Policy and practice in informal care, Buckingham, England: Open University Press.

Wuest, J. (1997) ‘Illuminating environmental influences on women’s caring', Journal of Advanced Nursing, 26(1): 49-58.

Yamamoto, N. and Wallhagen, M.I. (1998) 'Service use by family caregivers in Japan', Social Science and Medicine, 47(5): 677-691.

Zhan, J.H. and Montgomery, R. (2003) 'Gender and elder care in China: the influence of filial piety and structural constraints', Gender and Society, 17(2): 209-229. 